\title{
A Temperature Resistant Extracts Prepared from the Perinereis aibuhitensis and Its Antioxidative Characterization
}

\author{
Xuanjin $\mathrm{Wu}$ \\ College of Marine Life Science, Ocean University of China, 5 Yushan Road, 266003 Qingdao, \\ China \\ Zhongzheng Zhou \\ College of Marine Life Science, Ocean University of China, 5 Yushan Road, 266003 Qingdao, \\ China \\ Wei Wu
}

College of Marine Life Science, Ocean University of China, 5 Yushan Road, 266003 Qingdao, China

Yang Li

College of Marine Life Science, Ocean University of China, 5 Yushan Road, 266003 Qingdao, China

Ming Kong

College of Marine Life Science, Ocean University of China, 5 Yushan Road, 266003 Qingdao, China

Xiguang Chen (Corresponding author)

College of Marine Life Science, Ocean University of China, 5 Yushan Road, 266003 Qingdao, China, Tel: 86-0532-82032586 E-mail: xgchen@ouc.edu.cn

${ }^{1}$ These authors contributed to the work equally and should be regarded as co-first authors.

Received: March 21, 2019 Accepted: April 15, 2019 Published: April 16, 2019

doi:10.5296/ast.v7i2.14673 URL: https://doi.org/10.5296/ast.v7i2.14673

\begin{abstract}
The Perinereis aibuhitensis ( $P$. aibuhitensis), a traditional Chinese medicine, has a function of delaying senility-according to "Compendium of Materia Medica". It is considered a useful animal model in antioxidant activity tests. The P. aibuhitensis has already been utilized as biochemical responses to specific pollutants and the food supply for various birds. In the
\end{abstract}


present work, the extracts from $P$. aibuhitensis were prepared by the traditional decocting method and the biocompatibility was characterized by hemolysis and MTT tests. The materials showed no hemolytic for the hemolysis rate (lower than $0.2 \%$ ) while exhibited moderate cytotoxic effects on HUVECs (Human Umbilical Vein Endothelial Cells). In extracellular antioxidant activity against $\mathrm{O}_{2}{ }^{-}$and $\cdot \mathrm{OH}$, the extracts from $P$. aibuhitensis could eliminate $\mathrm{O}_{2}^{-}$and $\cdot \mathrm{OH}$ efficiently. In cellular ROS level tests, the ROS level was reduced effectively after treated with $P$. aibuhitensis extracts. The extracts had a potential prospect as a biological antioxidant to reduce redundant reactive oxygen species damage and great significance for humans health.

Keywords: P. aibuhitensis, biocompatibility, antioxidant activity, biological antioxidant

\section{Introduction}

The $P$. aibuhitensis, a marine invertebrate, is a conspicuous elements of benthos in intertidal mudflats and estuaries with a worldwide distribution (Zhang et al., 2008). They form an important part of the food supply for various birds and bottom-dwelling fishes. P. aibuhitensis has already been utilized in ancient China. Besides, the $P$. aibuhitensis was used as a traditional Chinese medicine to delay senility according to "Compendium of Materia Medica", which the special characteristic of $P$. aibuhitensis might relate with the scavenge of ROS in the point of modern medicine.

Much attention has been focused on the P. aibuhitensis in recent years because several bioactive components have been identified from $P$. aibuhitensis including antimicrobial peptide (Pan, 2004), glycerophospholipids (Hirobe et al., 2015) and protease (Li et al., 2006), etc. Owing to $P$. aibuhitensis good adaptability to stressful environmental conditions, some researchers have regarded them as biochemical responses to specific pollutants as well as potentially ecological keystone species for monitoring programs (Perez, Blasco, \& Sole, 2004).

It is well known that free radicals oxidative stress can damage cellular lipids, proteins, or DNA and inhibit their normal function (Valko et al., 2007). Furthermore, free radicals have been proved to be implicated in the pathogenesis of a variety of human diseases such as atherosclerosis, diabetes mellitus, hypertension and inflammation (Lowenfeld et al., 2017). Among free radicals, reactive oxygen species such as hydrogen peroxide $\left(\mathrm{H}_{2} \mathrm{O}_{2}\right)$, hydroxyl radical $(\mathrm{OH})$, and superoxide anion $\left(\mathrm{O}_{2}^{-}\right)$are usually generated during cellular metabolism (Yuan, Chen, Zhou, Liu, \& Yang, 2010). Hydroxyl radical is a neutral form from hydroxide ion and has a high reactivity, making it a very dangerous radical to the human cells (Du et al., 2017). Superoxide anion, a primary species of reactive oxygen species (ROS) function as a defense against viral or bacterial attack, also lead to damage of proteins, DNA, and lipid structures in human body (Tian, Mao, Okajima, \& Ohsaka, 2005; Wang et al., 2013). Hence, for protecting the organisms' health, removing the redundant reactive oxygen species are of great significance in a variety of in vitro and in vivo models.

It has reported that several environmental contaminants including heavy metals can induce oxidative stress in marine animals by generating reactive oxygen species(Yuan et al., 2010). 
Moreover, nowadays researcher were focused on identifying natural antioxidants and a lot of papers have been published on this topic (A., 2018; Butterfield, 2015; Ott et al., 2017; Qiao et al., 2018). Tian et al have found that the antioxidant system of $P$. aibuhitensis has defensive responses to $\mathrm{Pb}^{2+}$ exposure (Tian, Liu, Wang, Zhou, \& Tang, 2014). Hence, P. aibuhitensis is a good model animal for the study of the antioxidant activity via bioassays in laboratory.

In the current study, the extracts from $P$. aibuhitensis were prepared by the traditional decocting method and the biocompatibility such as blood compatibility and cytotoxicity were evaluated by hemolysis rate and MTT assay, respectively. To reflect antioxidant activity of extracts completely, the scavenging rate of $\mathrm{O}_{2}^{-}$and $\cdot \mathrm{OH}$ was measured in different temperature and concentration. Then, cellular ROS levels were evaluated after the treatments with different concentration of $P$. aibuhitensis extracts. The results indicated that the $\mathrm{O}_{2}^{-}$ and $\cdot \mathrm{OH}$ could be eliminated by $P$. aibuhitensis extracts. The antioxidant potential of $P$. aibuhitensis extracts showed a good prospect as a biological antioxidant.

\section{Materials and Methods}

\subsection{Materials}

Adult individuals of $P$. aibuhitensis were purchased from Marine Biology Institute of Shandong Province. Tris-HCl ( $\mathrm{pH}$ 8.2), DL-Dithiothreitol (DTT), and Pyrogallol were obtained from Qingdao Yunshan Biotechnology Co., Ltd. Phosphate buffer solution (PB), 1,10-Phenanthroline, $\mathrm{FeSO}_{4}$ and $\mathrm{H}_{2} \mathrm{O}_{2}$ were purchased from Huasheng Chemical. Other reagents were all analytical grade.

\subsection{Preparation of P. Aibuhitensis Extracts}

Fresh individuals of $P$. aibuhitensis were rinsed with tap water and distilled water several times to remove impurities. Then the clamworm was immersed into the distilled water for 12 $\mathrm{h}$. Subsequently, the clamworm was added into a beaker with fresh distilled water and boiled for $3 \mathrm{~h}$. Fresh distilled water was supplemented during the boiling process to avoid burning dry. The obtained extracts were filtered and freeze-dried which were used in the following experiments.

\subsection{Hemolysis Rate of P. Aibuhitensis Extracts}

The hemolysis rate of four different concentrations of extracts was evaluated. In brief, the hemodilution was prepared at $37^{\circ} \mathrm{C}$ for $1 \mathrm{~h} .20 \mu \mathrm{l}$ blood was added into the extract solution $(1 \mathrm{ml})$ and treated for $1 \mathrm{~h}$ at $37^{\circ} \mathrm{C}$. Then the mixture was centrifuged 5 minutes at 2000 $\mathrm{rpm} / \mathrm{min}$ to obtain the supernatant. The negative control groups were administered with normal physiological saline. The absorbance was measured at $316 \mathrm{~nm}$. The ratio of hemolysis rate (HR \%) was calculated which is defined as:

$$
\mathrm{HR} \%=\left(D_{\text {sample }}-D_{n c}\right) /\left(D_{p c}-D_{n c}\right) \times 100 \%
$$

Where $D_{\text {sample }}$ was the absorbance of sample group; $D_{n e}$ represented the absorbance of the 
normal saline groups; $D_{p c}$ was the absorbance of deionized water group.

\subsection{Cytotoxicity Assays of Extracts from P. Aibuhitensis}

In vitro cell viability in the presence of extracts from $P$. aibuhitensis was investigated by the MTT assay using human umbilical vein endothelial cells (HUVECs). HUVECs were seeded into a 96-well plate at a density of $1 \times 10^{4}$ cells per well and incubated for $24 \mathrm{~h}$ at $37{ }^{\circ} \mathrm{C}, \mathrm{CO}_{2}$ $5 \%$ with culture medium. The medium was removed and replaced by $100 \mu 1$ extracts solutions at $0.0125,0.025,0.05$, and $0.1 \mathrm{mg} / \mathrm{ml}$ and incubated for $24 \mathrm{~h}$ and $48 \mathrm{~h}$. Culture medium was used as blank control. At the end of the incubating, MTT $(10 \mu \mathrm{l})$ was added and the plates were incubated for an additional $4 \mathrm{~h}$. Then the supernatants were removed, and 100 $\mu \mathrm{l}$ DMSO was added to dissolve the blue-violet crystals for $10 \mathrm{~min}$. The absorbance was measured at $490 \mathrm{~nm}$. The relative growth rate (RGR) was expressed by the following equation:

$$
\operatorname{RGR}(\%)=D_{t} / D_{n e} \times 100 \%
$$

Where $D_{t}$ and $D_{n e}$ were the absorbances of the tested sample and the negative control.

\subsection{Antioxidant Activity}

\subsubsection{Determination of Antioxidant Activity Using Superoxide Anion $\left(\mathrm{O}_{2}^{-}\right)$Radical Scavenging Method}

The antioxidant activities were determined using $\mathrm{O}_{2}^{-}$as a model free radical. In the experiment, different concentrations of $P$. aibuhitensis extracts were used to evaluate its antioxidation. Briefly, the extracts were added into solution contained $5 \mathrm{ml} 0.1 \mathrm{~mol} / \mathrm{ml}$ Tris- $\mathrm{HCl}$, followed by adding $40 \mu 125 \mathrm{mmol} / \mathrm{l}$ pyrogallol to react in a shaker at $25{ }^{\circ} \mathrm{C}$ for 3 min accurately. At last, $50 \mu 150 \mathrm{mg} / \mathrm{ml}$ DTT was added into the mixed solution to stop the reaction and the solution was remained $10 \mathrm{~min}$ at room temperature. The absorbance was measured at $316 \mathrm{~nm}$. The $\mathrm{O}_{2}^{-}$scavenging activity was expressed by the following equation:

$$
\mathrm{O}^{-} \text {scavenging activity }(\%)=\left(A_{0}-A_{1}+A_{2}\right) / A_{0} \times 100 \%
$$

Where $A_{0}$ was the absorbance of the autoxidation of pyrogallol; $A_{1}$ represented the absorbance of the pyrogallol which had been in contact with sample (extract from $P$. aibuhitensis); $A_{2}$ was the absorption of sample.

\subsubsection{Determination of Antioxidant Activity Using · OH Radical Scavenging Method}

The antioxidant activities were determined using $\cdot \mathrm{OH}$ as another model free radical. In brief, $1 \mathrm{ml}$ of extraction from $P$. aibuhitensis was used and $0.15 \mathrm{~mol} / \mathrm{l}$ phosphate buffer saline $(\mathrm{pH}$ 7.4) was prepared as a stock standard. Samples were incubated at $37^{\circ} \mathrm{C}$ for $1 \mathrm{~h}$, after that, 
1,10-Phenanthroline monohydrate was added. Followed by adding $\mathrm{FeSO}_{4}$ and $\mathrm{H}_{2} \mathrm{O}_{2}$ and keeping reacting $10 \mathrm{~min}$ at $37^{\circ} \mathrm{C}$. The absorbance was measured at $536 \mathrm{~nm}$. The $\cdot \mathrm{OH}$ scavenging activity was expressed by the following equation:

\section{OH scavenging activity $(\%)=\left(A_{1}-A_{0}-A_{2}\right) /\left(A_{3}-A_{2}\right) \times 100 \%$}

Where $A_{1}$ represented the absorbance of 1,10-Phenanthroline monohydrate which had been in contact with sample; $A_{2}$ was the absorbance of 1,10-Phenanthroline monohydrate, $\mathrm{FeSO}_{4}$ and $\mathrm{H}_{2} \mathrm{O}_{2} ; A_{3}$ was the absorbance of 1,10 -Phenanthroline monohydrate with $\mathrm{FeSO}_{4} ; A_{0}$ was the absorption of sample.

\subsection{Determination of Cellular ROS Levels}

Cellular ROS levels of fibroblasts cell line (L929) treated with extracts from P. aibuhitensis were investigated with reactive oxygen species assay kit. L929 cells were cultured in Dulbecco's modified Eagle medium (DMEM) supplemented with $10 \%$ FBS and penicillin-streptomycin at $37{ }^{\circ} \mathrm{C}$ and $5 \% \mathrm{CO}_{2}$. Then, L929 cells were seeded in wells of 96 well plate at a density of $6 \times 10^{4}$ cells/well (Huang, Zhang, Yang, Zhang, \& Xu, 2013; Yan et al., 2016). Subsequently, the medium was replaced with fresh medium with a gradient concentration of $P$. aibuhitensis extracts (ranging from $2.5 \mathrm{mg} / \mathrm{ml}$ to $10 \mathrm{mg} / \mathrm{ml}$ ). The cells were incubated with carboxy-2',7'-dichloro-dihydro-fluorescein diacetate (DCFH-DA) probe for $20 \mathrm{~min}$. The cells were dealt with Rosup as positive control. The fluorescence of each group was measured at $488 \mathrm{~nm}$ (excitation) and $525 \mathrm{~nm}$ (emission) wavelengths on confocal laser scanning microscope.

\subsection{Statistical Analysis}

The assays were performed at least in triplicate on separate occasions. A statistical analysis was performed using one-way ANOVA for data. $p<0.05$ was considered as significant.

\section{Results}

\subsection{Hemolysis rate of P. aibuhitensis Extracts}

The $P$. aibuhitensis extracts were successfully prepared and the hemolysis rate was evaluated. As $100 \%$ and $0 \%$ values we used normal saline and deionized water, respectively. The extracts with the concentration range from $0.1 \mathrm{~g} / \mathrm{ml}$ to $0.4 \mathrm{~g} / \mathrm{ml}$ caused $0.29 \%$ up to $1.72 \%$ hemolysis (Fig. 1). According to the relative of the hemolysis rate and hemolysis level, the material showed no hemolytic that the hemolysis rate was lower than $0.2 \%$. The data showed that the extracts had excellent blood compatibility as biological antioxidant. 


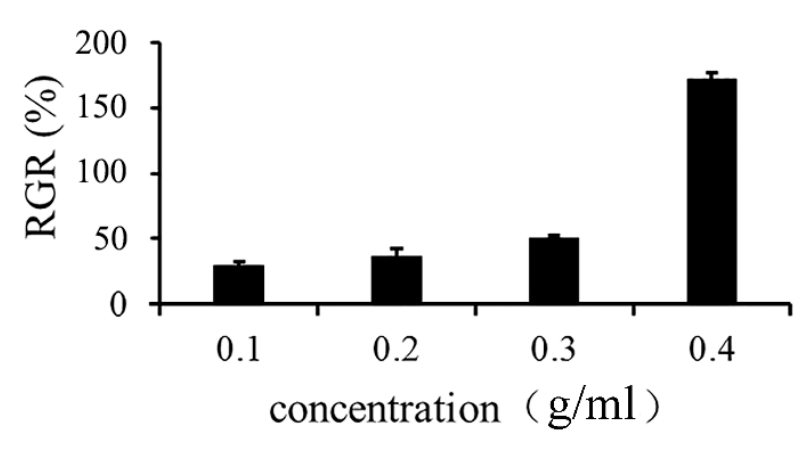

Fig. 1. Hemolysis rate of the extracts with different concentrations

\subsection{Cytotoxicity Assays of Extracts from P. aibuhitensis}

To determine effects of the extracts on biological antioxidant, the MTT test was used. Cells were immersed in the extract solution with the concentration range of $0.0125-0.1 \mathrm{mg} / \mathrm{ml}$ and treated for up to $48 \mathrm{~h}$ (Fig. 2). The data showed that the extract solution was non-toxic to HUVECs with other concentration range from $0.0125 \mathrm{mg} / \mathrm{ml}$ to $0.05 \mathrm{mg} / \mathrm{ml}$ and all the relative growth rates were nearly $100 \%$, which only exhibited moderate cytotoxic effects at the concentration of $0.1 \mathrm{mg} / \mathrm{ml}$. The result demonstrated that the extracts showed perfect cellular compatibility and a good candidate as biological antioxidant.

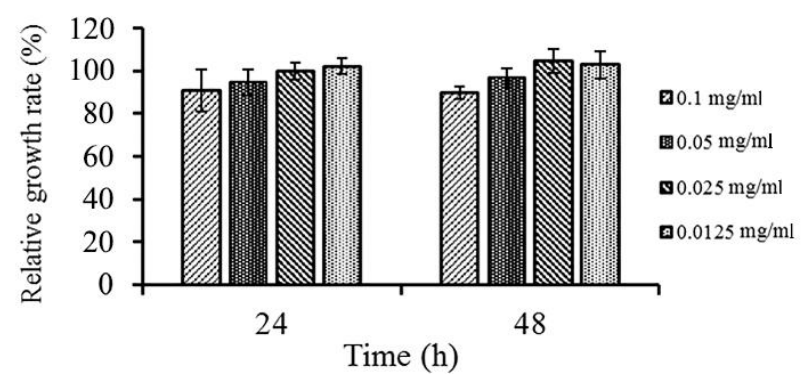

Fig. 2. Cell viability measured by MTT assay for the extracts from P. aibuhitensis with different concentrations after $24 \mathrm{~h}$ and $48 \mathrm{~h}$ incubation

\subsection{Antioxidant Activity}

\subsection{1 $\mathrm{O}_{2}^{-}$Scavenging Activity of the Extracts from P. aibuhitensis}

Superoxide anion $\left(\mathrm{O}_{2}^{-}\right)$could be generated during the process of pyrogallol auto-oxidation. With this method, the extracts from $P$. aibuhitensis were studied as scavengers of $\mathrm{O}_{2}^{-}$ generated by autoxidation of pyrogallol. The scavenging activity of the extract $(40 \mathrm{mg} / \mathrm{ml})$ was tested at different time ranging from 5 to 30 min Fig. 3 showed that the $\mathrm{O}_{2}{ }^{-}$scavenging rate changed slightly over time (near $65 \%$ ), which indicated that the extracts had accomplished the action of scavenging within $5 \mathrm{~min}$. 


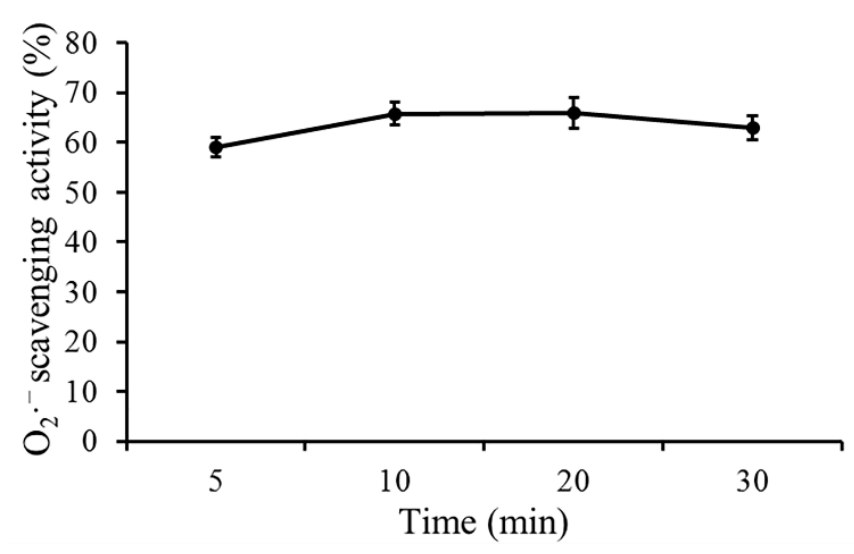

Fig. 3. Antioxidant activity of the extracts measured by pyrogallol auto-oxidation method

To reflect antioxidant activity completely, the extracts concentration and temperature were also considered as main facts to evaluate the antioxidant activity of extracts. The scavenging rates at $37{ }^{\circ} \mathrm{C}$ were slightly higher than that of $25^{\circ} \mathrm{C}$ (Fig. 4). It indicated that temperature had no apparent influence on the antioxidant activity of extracts. As $\mathrm{O}_{2}^{-}$is an undesirable compound especially in food industry which may be detrimental to health, the development of biological antioxidant become urgent. According to the results, the extracts from $P$. aibuhitensis could eliminate $\mathrm{O}_{2}^{-}$efficiently, then it had a wide application with different surrounding conditions as biological antioxidant.

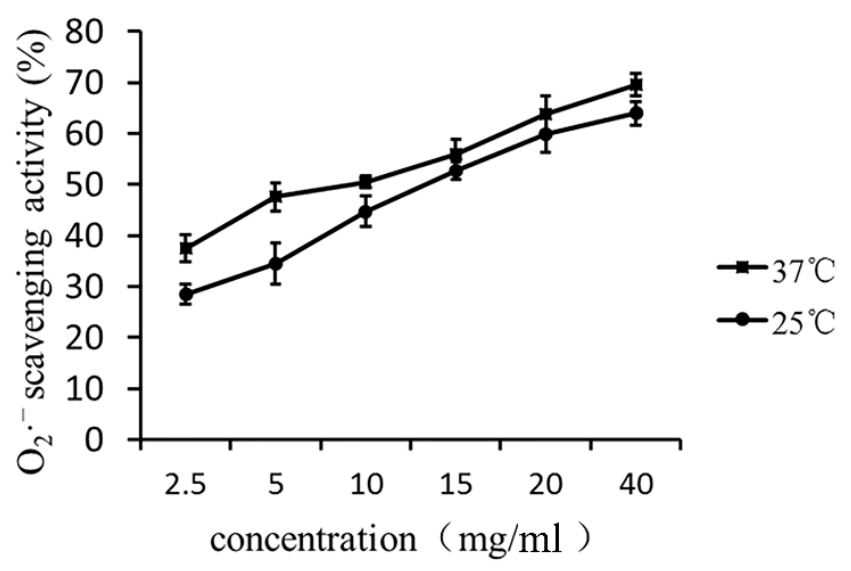

Fig. 4. Antioxidant activity of the extracts with gradient concentration at room temperatures and $37^{\circ} \mathrm{C}$

\subsubsection{OH Radical Scavenging Activity of the Extracts from P. aibuhitensis}

Hydroxyl Radical (.OH radical) is easily generated in damaged tissue and has powerful oxidization capacity. The redundant hydroxyl radical should be removed because of its ability of destroying cell membranes and DNA. In this study, the $\cdot \mathrm{OH}$ radical scavenging activity of the extracts from $P$. aibuhitensis was evaluated (Fig. 5). With the concentration increased, $\cdot \mathrm{OH}$ radical scavenging activity of the extracts improved rapidly and achieved approximately $60 \%$ at the concentration of $40 \mathrm{mg} / \mathrm{ml}$. In addition, compared with $\mathrm{O}_{2}^{-}$ 
scavenging activity, the low concentration extracts showed lower scavenging effect on $\cdot \mathrm{OH}$ radical $(<40 \mathrm{mg} / \mathrm{ml})$.

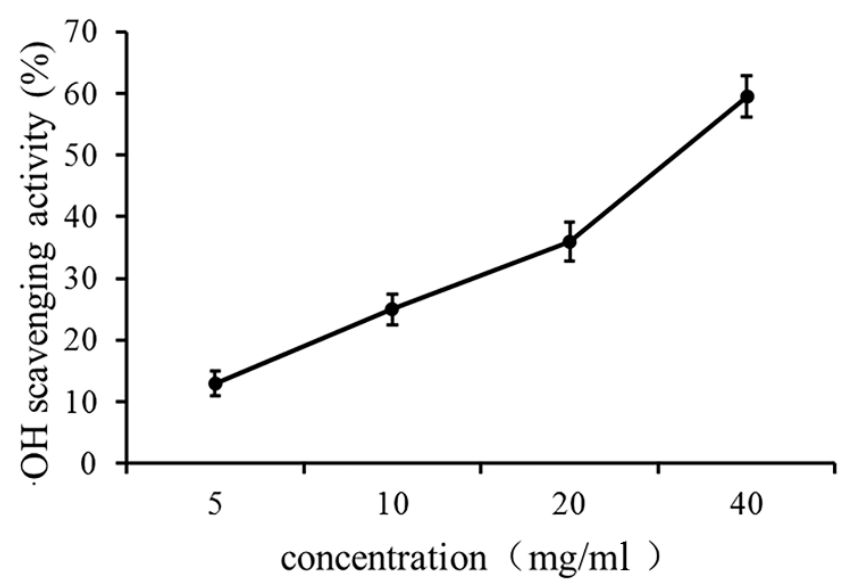

Fig. 5. $\cdot$ OH radical scavenging activity of extracts with different concentrations

\subsection{Cellular ROS Level}

In this study, the ROS in L929 cells was removed by the treatment of the extracts after 20 min incubation, which presented that the green fluorescent in experimental groups' cells became significantly weaker than the control. Moreover, the fluorescent decreased with the increase of concentrations of $P$. aibuhitensis extracts (from 2.5 to $10 \mathrm{mg} / \mathrm{ml}$ ) (Fig. 6 (a), (b) and (c)). The data showed that the extract of $P$. aibuhitensis could diffuse into cells easily and cause a chemical reaction with ROS, which reduced cellular ROS level effectively.
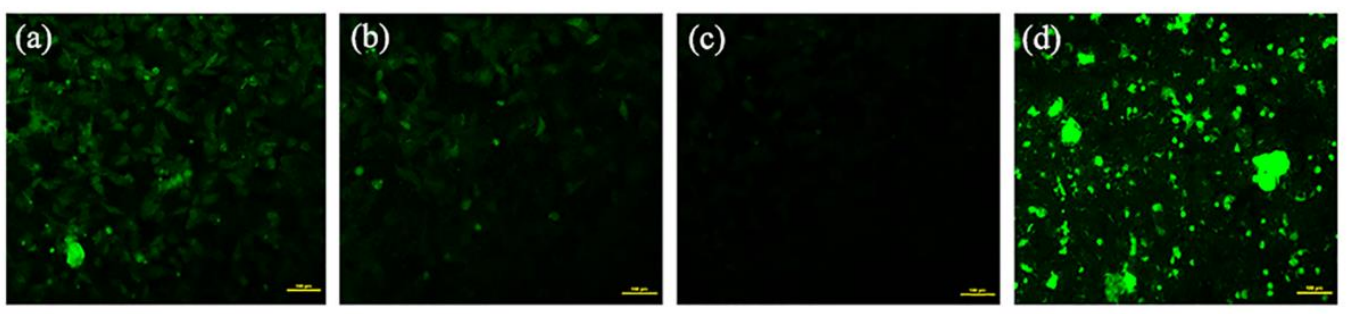

Fig. 6. The fluorescence photograph of cells treated with P. aibuhitensis extracts. (a), (b) and (c) represent the cell with different concentration of $P$. aibuhitensis extract ranging from 2.5 to $10 \mathrm{mg} / \mathrm{ml}$, respectively. D means the blank control

\section{Discussion}

The $P$. aibuhitensis was used as a traditional Chinese medicine in the forms of individuals, which had the function in delaying senility. In the study, the $P$. aibuhitensis extracts were successfully prepared with traditional decocting method and the characteristics of extracts were evaluated and made a preliminary research with the active ingredient firstly.

As biological antioxidant, the material should be safe and nontoxicity (Morales et al., 2014). The hemolysis rate and cellular compatibility were evaluated to study the biocompatibility of P. aibuhitensis extracts. The break rate of red blood cells was used to quantify the hemolysis 
properties of the extracts from $P$. aibuhitensis. The extracts displayed no hemolytic effects up to $0.4 \mathrm{mg} / \mathrm{ml}$, which indicated that the extracts had no detectable disturbance of red blood cells membranes. In addition, the extracts from $P$. aibuhitensis were obtained by the traditional decocting method which had the characteristics of safety and non-toxic to HUVECs. We could conclude that the extracts had excellent biocompatibility as biological antioxidant.

In humans, oxidative damage is usually not involved in the initiation of chronic disease although it can be a promoter of disease (MacDonald-Wicks, Wood, \& Garg, 2006). To remove redundant reactive oxygen species are of great significance for human health. The extracts from $P$. aibuhitensis could eliminate $\mathrm{O}_{2}^{-}$and $\cdot \mathrm{OH}$ efficiently in this study. The scavenging rate or antioxidant activity was enhanced with increasing concentration of the extracts. It was also proved that the extracts had a wide application with different-conditions (different time and temperature). The DCFH oxidation method was used for the quantitation of oxidative burst activity at a single-cell level. The non-fluorescent substrate, 2,7-dichlorofluorescin-diacetate (DCFH-DA), diffused through the plasma membrane and was trapped within the cell upon hydrolysis to DCFH. Intracellular oxidation turned DCFH into 2,7-dichlorofluorescein (DCF) with green fluorescent which could be clearly detected (Aranda et al., 2013; Christensen, Korsholm, Andersen, \& Agger, 2011). The extracts from $P$. aibuhitensis could reduce cellular ROS level effectively and the results was consistent with that of in vitro model against $\mathrm{O}_{2}{ }^{-}$and $\cdot \mathrm{OH}$. In the experiment, it was confirmed that the extracts from $P$. aibuhitensis had antioxidant activity against $\mathrm{O}_{2}^{-}$and $\cdot \mathrm{OH}$. During the process of decocting, the majority of protein would inactivate and degrade to short peptide with small molecular weight. In this way, the short peptide might be the main factors to scavenge the free radicals in the extracts (data not shown). And more experiment should be done to determine the active ingredients of extracts.

\section{Conclusions}

The extracts from $P$. aibuhitensis were prepared by the traditional decocting method and it showed perfect cellular compatibility and benign antioxidant activity against $\mathrm{O}_{2}{ }^{-}$and $\cdot \mathrm{OH}$. The cellular ROS level reduced effectively after the treatment with P. aibuhitensis extraction. Moreover, the fluorescent decreased with the increase of concentrations of P. aibuhitensis extracts. Future experiments will aim to determine the active ingredients of extracts. In summary, P. aibuhitensis exracts had a potential prospect as a biological antioxidant.

\section{Acknowledgements}

This work was supported by The Key Research and Investigate Plan of Shandong Province (2016YYSP014), and the Taishan Scholar Program, China.

\section{References}

Aranda, A., Sequedo, L., Tolosa, L., Quintas, G., Burello, E., Castell, J. V., \& Gombau, L. (2013). Dichloro-dihydro-fluorescein diacetate (DCFH-DA) assay: a quantitative method for oxidative stress assessment of nanoparticle-treated cells. Toxicol In Vitro, 27(2), 954-963. https://doi.org/10.1016/j.tiv.2013.01.016 
Butterfield, L. H. (2015). Cancer vaccines. BMJ, 350, h988. https://doi.org/10.1136/bmj.h988

Christensen, D., Korsholm, K. S., Andersen, P., \& Agger, E. M. (2011). Cationic liposomes as vaccine adjuvants. Expert Rev Vaccines, 10(4), 513-521. https://doi.org/10.1586/erv.11.17

Du, G., Hathout, R. M., Nasr, M., Nejadnik, M. R., Tu, J., Koning, R. I., \& Monkare, J. (2017). Intradermal vaccination with hollow microneedles: A comparative study of various protein antigen and adjuvant encapsulated nanoparticles. J Control Release, 266, 109-118. https://doi.org/10.1016/j.jconrel.2017.09.021

Hirobe, S., Azukizawa, H., Hanafusa, T., Matsuo, K., Quan, Y. S., Kamiyama, F., \& Nakagawa, S. (2015). Clinical study and stability assessment of a novel transcutaneous influenza vaccination using a dissolving microneedle patch. Biomaterials, 57, 50-58. https://doi.org/10.1016/j.jconrel.2017.09.021

Huang, Y., Zhang, L., Yang, J., Zhang, X., \& Xu, M. (2013). Structure and Properties of Cellulose Films Reinforced by Chitin Whiskers. Macromolecular Materials and Engineering, 298(3), 303-310. https://doi.org/10.1002/mame.201200011

Li, R. G., Qian, D. M., Guo, D. S., Du, G. C., Yan, Z. Y., \& Wang, B. (2006). Isolation of a cDNA Encoding a Protease from Perinereis aibuhitensis Grube. Acta Biochimica et Biophysica Sinica, 38(8), 543-548. https://doi.org/10.1111/j.1745-7270.2006.00192.x

Lowenfeld, L., Mick, R., Datta, J., Xu, S., Fitzpatrick, E., Fisher, C. S., ... Czerniecki, B. J. (2017). Dendritic Cell Vaccination Enhances Immune Responses and Induces Regression of HER2(pos) DCIS Independent of Route: Results of Randomized Selection Design Trial. Clin Cancer Res., 23(12), 2961-2971. https://doi.org/10.1158/1078-0432.CCR-16-1924

MacDonald-Wicks, L. K., Wood, L. G., \& Garg, M. L. (2006). Methodology for the determination of biological antioxidant capacityin vitro: a review. Journal of the Science of Food and Agriculture, 86(13), 2046-2056. https://doi.org/10.1002/jsfa.2603

Morales, P., Ferreira, I. C. F. R., Carvalho, A. M., Sánchez-Mata, M. C., Cámara, M., Fernández-Ruiz, V., \& Tardío, J. (2014). Mediterranean non-cultivated vegetables as dietary sources of compounds with antioxidant and biological activity. LWT - Food Science and Technology, 55(1), 389-396. https://doi.org/10.1016/j.lwt.2013.08.017

Ott, P. A., Hu, Z., Keskin, D. B., Shukla, S. A., Sun, J., Bozym, D. J., \& Wu, C. J. (2017). An immunogenic personal neoantigen vaccine for patients with melanoma. Nature, 547(7662), 217-221. https://doi.org/10.1038/nature22991

Pan, W. (2004). Perinerin, a Novel Antimicrobial Peptide Purified from the Clamworm Perinereis aibuhitensis Grube and Its Partial Characterization. Journal of Biochemistry, 135(3), 297-304. https://doi.org/10.1093/jb/mvh036

Perez, E., Blasco, J., \& Sole, M. (2004). Biomarker responses to pollution in two invertebrate species: Scrobicularia plana and Nereis diversicolor from the Cadiz bay (SW Spain). Mar Environ Res, 58(2-5), 275-279. https://doi.org/10.1016/j.marenvres.2004.03.071 


\section{Macrothink}

Aquatic Science and Technology

ISSN 2168-9148

2019, Vol. 7, No. 2

Qiao, D., Liu, L., Chen, Y., Xue, C., Gao, Q., Mao, H. Q., ... Chen, Y. (2018). Potency of a Scalable Nanoparticulate Subunit Vaccine. Nano Lett, 18(5), 3007-3016. https://doi.org/10.1021/acs.nanolett.8b00478

Rode, A. (2018). Nanocarriers A Novel Approach for Enhanced Drug Delivery through Skin. Asian Journal of Pharmaceutics, 12(01), S13-S20.

Tian, Y., Liu, H., Wang, Q., Zhou, J., \& Tang, X. (2014). Acute and chronic toxic effects of $\mathrm{Pb}(2)(+)$ on polychaete Perinereis aibuhitensis: morphological changes and responses of the antioxidant system. J Environ Sci (China), 26(8), 1681-1688.

https://doi.org/10.1016/j.jes.2014.06.008

Tian, Y., Mao, L., Okajima, T., \& Ohsaka, T. (2005). A carbon fiber microelectrode-based third-generation biosensor for superoxide anion. Biosens Bioelectron, 21(4), 557-564.

https://doi.org/10.1016/j.bios.2004.12.006

Valko, M., Leibfritz, D., Moncol, J., Cronin, M. T., Mazur, M., \& Telser, J. (2007). Free radicals and antioxidants in normal physiological functions and human disease. Int J Biochem Cell Biol, 39(1), 44-84. https://doi.org/10.1016/j.biocel.2006.07.001

Wang, L., Wen, W., Xiong, H., Zhang, X., Gu, H., \& Wang, S. (2013). A novel amperometric biosensor for superoxide anion based on superoxide dismutase immobilized on gold nanoparticle-chitosan-ionic liquid biocomposite film. Anal Chim Acta, 758, 66-71. https://doi.org/10.1016/j.aca.2012.10.050

Yan, D., Zhou, Z. Z., Jiang, C. Q., Cheng, X. J., Kong, M., Liu, Y., \& Chen, X. G. (2016). Sodium carboxymethylation-functionalized chitosan fibers for cutaneous wound healing application. Frontiers of Materials Science. https://doi.org/10.1007/s11706-016-0353-9

Yuan, X., Chen, A., Zhou, Y., Liu, H., \& Yang, D. (2010). The influence of cadmium on the antioxidant enzyme activities in polychaete Perinereis aibuhitensis Grube (Annelida: Polychaeta). Chinese Journal of Oceanology and Limnology, 28(4), 849-855. https://doi.org/10.1007/s00343-010-9127-x

Zhang, Q., Zhou, Q., Wang, J., Sun, S., Hua, T., \& Ren, L. (2008). Influences of Cu or Cd on the neurotoxicity induced by petroleum hydrocarbons in ragworm Perinereis aibuhitensis. Journal of Environmental Sciences, 20(3), 364-371.

https://doi.org/10.1016/S1001-0742(08)60057-1

\section{Copyright Disclaimer}

Copyright for this article is retained by the author(s), with first publication rights granted to the journal.

This is an open-access article distributed under the terms and conditions of the Creative Commons Attribution license (http://creativecommons.org/licenses/by/3.0/). 